OPEN ACCESS

Edited by:

John D. Imig,

Medical College of Wisconsin,

United States

Reviewed by:

Anne Dorrance,

Michigan State University,

United States

Ana Paula Davel,

State University of Campinas, Brazil

Jérémy Lagrange,

Johannes Gutenberg University

Mainz, Germany

*Correspondence:

Guido Lastra

lastrag@health.missouri.edu

Specialty section:

This article was submitted to

Vascular Physiology,

a section of the journal

Frontiers in Physiology

Received: 28 July 2020

Accepted: 17 February 2021

Published: 29 March 2021

Citation:

Manrique-Acevedo C, Padilla J, Naz H, Woodford ML, Ghiarone T,

Aroor AR, Hulse JL,

Cabral-Amador FJ, Martinez-Diaz V,

Hans $C P$, Whaley-Connell A,

Martinez-Lemus LA and Lastra G

(2021) Mineralocorticoid Receptor

in Myeloid Cells Mediates Angiotensin

II-Induced Vascular Dysfunction

in Female Mice.

Front. Physiol. 12:588358.

doi: 10.3389/fphys.2021.588358

\section{Mineralocorticoid Receptor in Myeloid Cells Mediates Angiotensin II-Induced Vascular Dysfunction in Female Mice}

\author{
Camila Manrique-Acevedo ${ }^{1,2,3}$, Jaume Padilla ${ }^{2,4}$, Huma Naz ${ }^{1,3}$, Makenzie L. Woodford ${ }^{2,4}$, \\ Thaysa Ghiarone'2, Annayya R. Aroor ${ }^{1,2}$, Jack L. Hulse', Francisco J. Cabral-Amador', \\ Vanesa Martinez-Diaz ${ }^{1}$, Chetan P. Hans ${ }^{2,5}$, Adam Whaley-Connell ${ }^{1,3,6}$, \\ Luis A. Martinez-Lemus ${ }^{2,7,8}$ and Guido Lastra ${ }^{1,3 *}$

\begin{abstract}
'Division of Endocrinology and Metabolism, Department of Medicine, University of Missouri, Columbia, MO, United States, ${ }^{2}$ Dalton Cardiovascular Research Center, University of Missouri, Columbia, MO, United States, ${ }^{3}$ Research Service, Harry S. Truman Memorial Veterans' Hospital, Columbia, MO, United States, ${ }^{4}$ Department of Nutrition and Exercise Physiology, University of Missouri, Columbia, MO, United States, ${ }^{5}$ Division of Cardiovascular Medicine, Department of Medicine, University of Missouri, Columbia, MO, United States, ${ }^{6}$ Division of Nephrology and Hypertension, Department of Medicine, University of Missouri, Columbia, MO, United States, ' Department of Biomedical, Biological and Chemical Engineering, University of Missouri, Columbia, MO, United States, ${ }^{8}$ Department of Medical Pharmacology and Physiology, University of Missouri, Columbia, MO, United States
\end{abstract}

Enhanced mineralocorticoid receptor (MR) signaling is critical to the development of endothelial dysfunction and arterial stiffening. However, there is a lack of knowledge about the role of MR-induced adipose tissue inflammation in the genesis of vascular dysfunction in women. In this study, we hypothesize that MR activation in myeloid cells contributes to angiotensin II (Ang II)-induced aortic stiffening and endothelial dysfunction in females via increased pro-inflammatory (M1) macrophage polarization. Female mice lacking MR in myeloid cells (MyMRKO) were infused with Ang II (500 ng/kg/min) for 4 weeks. This was followed by determinations of aortic stiffness and vasomotor responses, as well as measurements of markers of inflammation and macrophage infiltration/polarization in different adipose tissue compartments. MyMRKO mice were protected against Ang II-induced aortic endothelial stiffening, as assessed via atomic force microscopy in aortic explants, and vasorelaxation dysfunction, as measured by aortic wire myography. In alignment, MyMRKO mice were protected against Ang IIinduced macrophage infiltration and M1 polarization in visceral adipose tissue (VAT) and thoracic perivascular adipose tissue (tPVAT). Collectively, this study demonstrates a critical role of MR activation in myeloid cells in the pathogenesis of vascular dysfunction in females associated with pro-inflammatory macrophage polarization in VAT and TPVAT. Our data have potential clinical implications for the prevention and management of cardiovascular disease in women, who are disproportionally at higher risk for poor outcomes.

Keywords: arterial stiffening, macrophage, endothelium, inflammation, adipose tissue 


\section{INTRODUCTION}

Chronic inflammation is invariably present in the setting of cardiovascular disease (CVD) (Saltiel and Olefsky, 2017). In different models of renin-angiotensin-aldosterone system (RAAS) overactivation, inflammation promotes hypertrophy, remodeling, and dysfunction of cardiovascular tissue that ultimately results in clinical CVD (Saltiel and Olefsky, 2017). These conditions are also associated with inflammation of the adipose tissue (Brown et al., 2014). In turn, inflammation in fat tissue encompasses a distinctive macrophage infiltration and polarization pattern, characterized by a pro-inflammatory M1 phenotype at the expense of anti-inflammatory M2 macrophages (Kraakman et al., 2014; Lee et al., 2015). Activated immune cells promote oxidative stress in vascular tissues and contribute to the genesis of endothelial dysfunction and vascular stiffening (van Bussel et al., 2011; Aroor et al., 2013; Jain et al., 2014). These changes precede the development of hypertension and CVD (Kaess et al., 2012; Weisbrod et al., 2013).

Visceral adipose tissue (VAT) depots have been extensively associated with heightened CVD risk (Goodpaster et al., 2003; Klein, 2004; Fox et al., 2007). However, there is also growing interest in perivascular adipose tissue (PVAT) as it exhibits unique features that differentiate it from VAT or subcutaneous adipose tissue and has been shown to modulate the function of underlying blood vessels (Lastra and Manrique, 2015). Clinical studies have reported that dysfunctional PVAT contributes to increased risk for CVD independently of VAT (Lastra and Manrique, 2015). Enhanced RAAS activation impairs the normal vasodilatory and anti-contractile properties of PVAT, leading to inflammation, vasoconstriction, and vascular remodeling (Agabiti-Rosei et al., 2018; Dos Reis Costa et al., 2020).

RAAS activation leads to augmented mineralocorticoid receptor (MR) signaling (Lastra et al., 2008). MR is expressed in immune cells (Muñoz-Durango et al., 2015), and its stimulation leads to inflammation, oxidative stress, and vascular remodeling (Jaisser and Farman, 2016; Tesch and Young, 2017). Accordingly, MR deletion in myeloid cells has been shown to prevent macrophage polarization, cardiovascular fibrosis, and remodeling in male mice hypertensive models (Rickard et al., 2009; Usher et al., 2010; Shukri et al., 2018).

In the vasculature, mineralocorticoids elicit dimorphic responses that impact females to a greater extent compared to males (Mehta et al., 2016). Indeed, obese and insulinresistant women display more frequent and aggressive frequency of CVD compared to men (Nayyar et al., 2018). Although available clinical and preclinical studies have established that MR activation is critical to the development of vascular dysfunction impacting females more severely than males, there is still a lack of knowledge about the relationship between MR activation in myeloid cells and the development of vascular/endothelial dysfunction in females. In this study, we tested the hypothesis that MR activation in myeloid cells mediates aortic stiffening and endothelial dysfunction induced by a continuous infusion of angiotensin II (Ang II) in female mice, and that these vascular effects parallel with changes in adipose tissue macrophage infiltration and pro-inflammatory M1 polarization.

\section{MATERIALS AND METHODS}

\section{Animals}

Animal procedures were performed in accordance with the Institutional Animal Care and Use Committee (IACUC) at the University of Missouri-Columbia and National Institutes of Health guidelines. The IACUC at the University of MissouriColumbia reviewed and approved the animal protocol followed. Mice used in these experiments were harbored under a 12 $\mathrm{h}$ /day illumination regimen and fed with standard mouse chow and water for ad libitum consumption. Double floxed MR (MRFL2) mice were kindly provided by Dr. Richard Mortensen from the University of Michigan, and this model has been previously characterized (Berger et al., 2006; Usher et al., 2010). Briefly, MRFl2 were crossed with LysM-Cre mice (endogenous M lysozyme driving expression of Cre-recombinase, The Jackson Laboratory) in order to obtain myeloid-specific MR knockout mice (MRFl2/LysM-Cre+). Herein, we refer to MRFl2/LysMCre+ as "MyMRKO" and MR intact (MRFl2/LysM-Cre-) as littermate (LM) controls. We used ear punch and genotyping to detect the presence of both the floxed and deleted alleles, as previously described (Berger et al., 2006; Usher et al., 2010). Mice were infused with Ang II (500 ng/ $\mathrm{kg} / \mathrm{min}$ ) or saline for 4 weeks, as previously described in our laboratory (Brown et al., 2017). Both treatments were administered by micro-osmotic pump Model 1004 (ALZET, Cupertino, CA) located subcutaneously between the scapulae. Three cohorts of female mice were studied: LMsaline, LM-Ang II, and MyMRKO-Ang II. Separate cohorts of LM-Ang II and MyMRKO-Ang II mice were devoted to assessing macrophage infiltration and polarization in fat. A saline-infused MyMRKO cohort was not included in this investigation, as it has been previously reported that these mice do not exhibit phenotypical variations in cardiovascular tissue or macrophage infiltration/polarization under control conditions (Rickard et al., 2009; Usher et al., 2010).

Plasma insulin concentrations were determined using a commercially available, mouse-specific ELISA (Alpco Diagnostics, Salem, NH). Aldosterone levels were analyzed by radioimmunoassay at Michigan State University Diagnostic Veterinary Laboratory.

\section{Blood Pressure}

Systolic blood pressure in mice was determined non-invasively using a CODA tail-cuff blood pressure system (CODA-HT2; Kent Scientific, Torrington, CT) within 1 week of killing as previously described (Grunewald et al., 2019). Animals were acclimated to the restraints and tail-cuffs for a minimum of three consecutive days prior to blood pressure determination. A minimum of eight blood pressure readings were averaged for each animal.

\section{Aortic Stiffness}

Atomic force microscopy (AFM) was used to assess ex vivo endothelial stiffness in enface aortic preparations as previously described (Padilla et al., 2019). Perivascular fat and connective tissue were gently removed from the aortic explants as the piece of aorta needs to lay flat on a hard surface to be probed with the 
AFM cantilever. A total of at least 10 curves were obtained per cell/aortic explant site and repeated for at least four cells/sites per sample. Elastic moduli were calculated from the force curves by fitting them to the Hertz model of a conical tip using a custommade Python script as previously described (Hussain et al., 2014).

\section{Ex vivo Aortic Vasomotor Function}

Thoracic aortic 2-mm rings, cleaned of perivascular fat and connective tissue, were mounted in wire myograph organ bath chambers (620M, Danish Myo Technology, Hinnerup, Denmark) containing warmed physiological saline solution gassed with $95 \%$ $\mathrm{O}_{2}-5 \% \mathrm{CO}_{2}$ and maintained at $37^{\circ} \mathrm{C}$, as previously described (Grunewald et al., 2019; Padilla et al., 2019). Arterial rings were constricted with $\mathrm{KCl}(80 \mathrm{mM})$ to assess viability. After washout, aortas were then preconstricted with the prostaglandin H2/thromboxane A2 receptor agonist, U-46619 (20 nM). Relaxation of arterial rings to acetylcholine ( $\mathrm{ACh}, 10^{-9}$ to $10^{-5}$ $\mathrm{M}$ ), the NO-donor sodium nitroprusside (SNP, $10^{-9}$ to $10^{-4} \mathrm{M}$ ), and insulin (Novolin R, Novo Nordisk; $10^{-9}$ to $10^{-5} \mathrm{M}$ ) was assessed by cumulative addition of agonist to the vessel bath. Endothelium-dependent relaxation was assessed using $\mathrm{ACh}$ and insulin, while SNP assessed endothelium-independent relaxation. Area under the curve (AUC) of each concentration-response curve was calculated using the trapezoidal rule.

\section{RNA Isolation}

To perform relative quantification by Real-Time PCR (RT-PCR), total RNA was isolated from thoracic (tPVAT) and abdominal (aPVAT) aortic PVAT as well as $30-41 \mathrm{mg}$ of perigonadal fat, which is widely considered to be VAT in rodents (Bjørndal et al., 2011; Chusyd et al., 2016), per animal. After dissection, $1 \mathrm{ml}$ of QIAzol Lysis Reagent (Qiagen, Hilden, Germany) was added to each sample. Samples were stored at $-80^{\circ} \mathrm{C}$ until RNA isolation. Tissues were disrupted and homogenized in intervals of $2 \mathrm{~min}$ at $20 \mathrm{1} / \mathrm{s}$ by Tissulyser (Qiagen, Hilden, Germany) followed by $5 \mathrm{~min}$ of cooling on ice. This process was repeated three times. Then, RNA was concentrated and precipitated using RNeasy Lipid Tissue MiniKit (Qiagen, Hilden, Germany), following its commercial standard protocol. The optional digestion step with DNase, recommended by the protocol, was also performed using RNase-Free DNase Set (Qiagen, Hilden, Germany). DNase treatment was performed with $10 \mu \mathrm{l}$ of DNase I (27.27 Kunitz units) for $15 \mathrm{~min}$ at room temperature. Total RNA from tPVAT, aPVAT, and perigonadal adipose tissue (PGAT) was resuspended in 15 and $30 \mu \mathrm{l}$ of ultrapure water. The concentration and quality of RNA were measured using NanoDrop ND-1000 spectrophotometer (Thermo Fisher Scientific, Wilmington, DE). First-strand cDNA was synthesized from total RNA using the ImProm-II Reverse Transcription System kit (Promega, Madison, WI).

\section{Real-Time PCR}

Markers of inflammation and macrophage polarization were determined by relative quantification with RT-PCR on a CFX96 Touch Real Time PCR Detection System (Bio-Rad, Hercules, CA) using the iTaq Universal SYBR Green Supermix (Bio-Rad Laboratories, Hercules, CA) according to the manufacturer's instructions. Each experiment was performed with two technical replicates containing $12.5,15$, and 20 ng of complementary DNA of tPVAT, aPVAT, and PGAT, respectively, $10 \mu \mathrm{l}$ iTaq Universal SYBR Green Supermix (2X), and forward and reverse primers (10 pM/ml; Integrated DNA Technologies, San Diego, CA). The primer sequences used are listed in Table 1. A negative control was included for each primer pair in accordance with MIQE guidelines (Bustin et al., 2009). RT-PCR reaction conditions were as follows: one cycle of $95^{\circ} \mathrm{C}$ for $2 \mathrm{~min}$, followed by 39 cycles of $95^{\circ} \mathrm{C}$ for $5 \mathrm{~s}, 60^{\circ} \mathrm{C}$ for $30 \mathrm{~s}$, and one cycle more of $95^{\circ} \mathrm{C}$ for $5 \mathrm{~s}$. In order to check the specificity of the primers, a melting curve analysis for each amplicon was performed at the end of each run with a temperature gradient from 65 to $95^{\circ} \mathrm{C}$ with an increment of $0.5^{\circ} \mathrm{C} \mathrm{s}^{-1}$. Bio-Rad CFX manager software was used to obtain $\mathrm{Cq}$ value. Glyceraldehyde 3-phosphate dehydrogenase (GAPDH) was used as a housekeeping control gene. Calculations of gene expression were done using the $2^{-\Delta} \Delta \mathrm{Ct}$ method and presented as fold difference compared with the LM-Saline group, which was set to 1 . In order to standardize experimental protocols and their information for publication, these experiments adopted the Minimum Information for Publication of Quantitative Realtime PCR Experiments (MIQE) guidelines, which promote consistency between laboratories and increase experimental transparency (Bustin et al., 2009).

\section{Single-Cell Preparation From Adipose Tissue}

Visceral fat pads from the different cohorts were dissected and placed in buffer containing Hanks' balanced salt solution (HBSS) $+10 \%$ fetal bovine serum (FBS). Fat pads were cut and

TABLE 1 | Sequences of primers used in this investigation.

\begin{tabular}{ll}
\hline Gene studied & Primer sequence \\
\hline CD11b & Forward: 5'-CCA AGA CGA TCT CAG CAT-3' \\
& Reverse: 5'-TC TGG CTT GCT GAA TCC TT-3' \\
CD206 & Forward: 5'-CAA GGA AGG TTG GCA TाT GT-3' \\
& Reverse: 5'- CCT TTC AGT CCT TTG CAA GC-3' \\
GAPDH & Forward: 5'-GGA GAA ACC TGC CAA GTA TGA-3' \\
& Reverse: 5'- TCC TCA GTG TAG CCC AAG A-3' \\
CD11c & Forward: 5'-ACA CAG TGT GCT CCA GTA TGA-3' \\
& Reverse: 5'-GCC CAG GGA TAT GTT CAC AGC-3' \\
CD68 & Forward: 5'-CCC AAT TCA GGG TGG AAG AA-3' \\
& Reverse: 5'ATC CAA AGG TAA GCT GTC GAT AA-3' \\
TNF-a & Forward: 5'-GCC TCT TCT CAT TCC TGC TTG-3' \\
& Reverse: 5'-CTG ATG AGA GGG AGG CCA TT-3' \\
IL-6b & Forward: 5'-GAT AAG CTG GAG TCA CAG AAG G-3' \\
& Reverse: 5'-TTG CCG AGT AGA AGA TCT CAA AGT G-3' \\
IL-10 & Forward: 5'-CCA AGC CTT ATC GGA AAT GA-3' \\
& Reverse: 5'-TाT TCA CAG GGG AGA AAT CG-3' \\
MCP-1 & Forward: 5'-GTC TCA ACC AGA TGC AGT TAA T-3' \\
& Reverse: 5'-CTG CTG GTG ATT CTC TTG TAG TT-3' \\
NO $\times 2$ & Forward: 5'-CTT TGG TAC AGC CAG TGA AGA-3' \\
& Reverse: 5'-CCA GAC AGA CTT GAG AAT GGA G-3' \\
N0 $\times 4$ & Forward: 5' CTG GAC CTT TGT GCC TाT ATT G-3' \\
& Reverse: 5'-AGG GAT GAT TGA TGA CTG AGA TG-3'
\end{tabular}


minced in digestion buffer [HBSS, $20 \mathrm{~mm}$ 4-(2-hydroxyethyl)1-piperazineethanesulfonic acid (HEPES), 1\% bovine serum albumin (BSA), and $1 \mathrm{mg} / \mathrm{ml}$ collagenase type II] and incubated at $37^{\circ} \mathrm{C}$ for $45 \mathrm{~min}$. Digested tissue was passed through a $70-\mu \mathrm{m}$ cell strainer and centrifuged at $500 \times \mathrm{g}$ for $5 \mathrm{~min}$. Pelleted cells were resuspended, and red blood cell lysis buffer was added and kept at room temperature for $2 \mathrm{~min}$. Staining buffer was added and centrifuged at $500 \times \mathrm{g}$ for $5 \mathrm{~min}$, and the cell pellet was resuspended in staining buffer and used for flow staining.

\section{Flow Cytometry}

For antibody staining, $1 \times 10^{6}$ cells/sample were used. Surface antibodies (1:50 dilution) PE anti-mouse CD45 (clone: 30F11), APC/Cyanine7 anti-mouse F4/80 (clone: BM8), FITC anti-mouse CD11b (clone: M1/70), Pacific Blue ${ }^{\mathrm{TM}}$ anti-mouse CD11c (clone: N418), PerCP/Cyanine5.5 anti-mouse CD206 (clone:C068C2), and PE/Cyanine7 anti-mouse I-A/I-E (MHC-II) (clone: M5/114.15.2) were added and incubated for $30 \mathrm{~min}$ at $4^{\circ} \mathrm{C}$ in the dark. After staining, cells were washed twice with staining buffer, and pellets were dissolved in $400 \mathrm{ml}$ staining buffer before acquiring the samples. All the antibodies were obtained from BioLegend, San Diego, CA, United States. The data were collected using fluorescence activated cell sorting (FACS) Canto flow cytometer (BD Biosciences, Franklin Lakes, NJ, United States) and analyzed cytometry along with isotype controls using FlowJo software (Tarique et al., 2020).

\section{Histological Assessment Macrophage Infiltration in Visceral Adipose Tissue}

Formalin-fixed VAT samples were processed through paraffin embedding, sectioned at $5 \mu \mathrm{m}$, and stained with macrophage marker Mac-2 antibody (CL8942AP, 1:1,000; Cedarlane, Burlington, ON, CA), as previously described (Winn et al., 2019). Images were acquired with an Olympus IX51 microscope. Images were obtained by an investigator in a blinded manner, and objective quantification of macrophage infiltration was done by determining the positive Mac-2-stained area per $\times 10$ fields of view using ImageJ software (NIH public domain; National Institutes of Health, Bethesda, MD). Crown-like structure density was defined as Mac-2-positive stained area (Huang et al., 2013). The average of three X10 fields of view was determined for each animal.

\section{Aortic Inducible Nitric Oxide Synthase}

Formalin-fixed abdominal aorta samples were processed through paraffin embedding, sectioned at $5 \mu \mathrm{m}$, and stained with inducible nitric oxide synthase (iNOS) antibody (ab 15323, 1:200; Abcam, Cambridge, MA, United States). Specificity of the antibody was confirmed using appropriate IgG controls (I-10005; Vector Laboratories, Burlingame, CA) in place of the primary antibodies at the same concentrations as previously described (Hans et al., 2012; Sharma et al., 2019). iNOS-positive myeloid and endothelial cells were counted (three equally sized regions of interest per slide) visually on the basis of nuclear shape and size at $40 \times$ and $100 \times$ magnification. The immunostaining patterns were examined by two investigators in a blinded manner.

\section{Statistical Analysis}

Statistical analyses were performed using GraphPad Prism (version 8.2.0). All data were checked for normality by the Shapiro-Wilk test. Whenever data were not normally distributed, a logarithmic transformation was applied to normalize it. If transformations did not normalize data, we performed the equivalent non-parametric statistic test. Statistical comparisons were performed using one-way or two-way ANOVA followed by Tukey post hoc tests when applicable or Student's $t$-test, as appropriate. Values are expressed as means \pm standard error of the mean (SEM). Statistical significance was accepted at $p \leq 0.05$.

\section{RESULTS}

The average age of mice at the start of the experimental protocol was $22 \pm 1$ weeks. No differences in weight were found between the three cohorts (Table 2). We measured plasma aldosterone concentrations at the time of euthanasia in order to confirm the effect of Ang II infusion. As expected, aldosterone concentrations were significantly higher in Ang II-infused mice (Table 2). We also assessed insulin levels after a 5-h fast at the time of euthanasia. Our data did not reveal any significant differences across groups of mice (Table 2), thus suggesting that changes in neither body weight nor insulin concentrations account for the differences seen in vascular outcomes. Further, we assessed systolic blood pressure via the tail-cuff method. The 4-week infusion of Ang II resulted in a significant elevation in systolic blood pressure on both cohorts, and lack of MR in myeloid cells had no effect (Figure 1A).

We then examined aortic endothelial stiffness by AFM in thoracic aortic explants from the different cohorts. Of note, our group has previously shown that Ang II at the dose used in this study results in aortic stiffening measured in vivo by pulse wave velocity (Brown et al., 2017). Ang II infusion for 4 weeks resulted in a significant increase in endothelial stiffness relative to mice infused with saline. In turn, aortic stiffness was significantly reduced relative to littermates by the abrogation of $M R$ in

TABLE 2 | Body weight and insulin and plasma aldosterone levels in female MyMRKO and LM mice after treatment with Ang II (500 ng/ $/ \mathrm{kg} / \mathrm{min})$ or saline via osmotic minipumps for 4 weeks.

\begin{tabular}{lccc}
\hline & LM-Saline & LM-Ang II & MyMRKO-Ang II \\
\hline $\begin{array}{l}\text { Body } \\
\text { weight } \\
\text { (grams) }\end{array}$ & $21.4 \pm 0.6$ & $20.8 \pm 1.4$ & $20.4 \pm 1.9$ \\
$\begin{array}{l}\text { Insulin } \\
\text { (ng/dL) }\end{array}$ & $0.51 \pm 0.05$ & $0.32 \pm 0.22$ & $0.58 \pm 0.10$ \\
$\begin{array}{l}\text { Aldosterone } \\
\text { (pmol/L) }\end{array}$ & $2317.94 \pm 316.57$ & $6407.60 \pm 594.15^{\star}$ & $6332.08 \pm 447.07 \$$ \\
\hline
\end{tabular}

Samples were collected after 5-h fasting and prior to sacrifice. Results are presented as means \pm standard error (SE), $n=7-15$ for all groups.

LM, littermates; Ang II, Angiotensin II; MyMRKO, myeloid mineralocorticoid receptor knockout.

${ }^{*} p \leq 0.05$ LM-Ang /I vs. LM-Saline;\$ $p \leq 0.05$ MyMRKO-Ang /I vs. LM-Saline. 

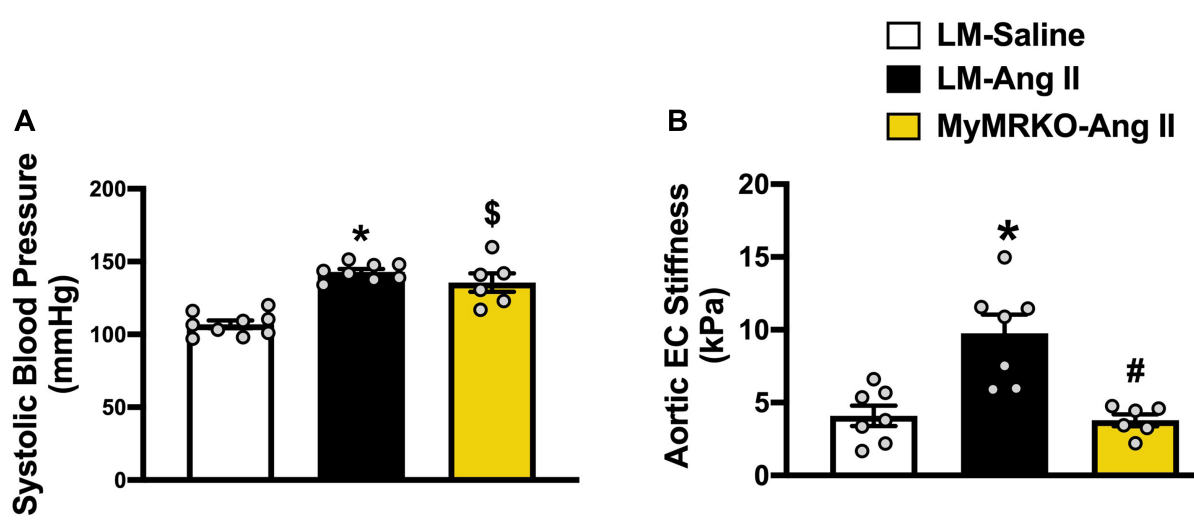

FIGURE 1 | Ang II-induced aortic stiffening is ameliorated by myeloid cell MR deletion. Systolic blood pressure (A) and ex vivo assessment of aortic endothelial stiffness by atomic force microscopy (B). ${ }^{*} p \leq 0.05$ LM-Ang II vs. LM-Saline; ${ }^{*} p \leq 0.05$ LM-Ang $\|$ vs. MyMRKO-Ang II; ${ }^{\$} p \leq 0.05$ MyMRKO-Ang II vs. LM-Saline. $n=6-9$ for all groups. EC, endothelial cell; LM, littermate; Ang II, angiotensin II; MyMRKO, myeloid mineralocorticoid receptor knockout.

myeloid cells (Figure 1B), therefore suggesting a protective effect of MyMRKO in myeloid cells on aortic endothelium.

Since vascular stiffness contributes to impaired vasodilatory function (Walker et al., 2015), we assessed aortic vasodilatory reaction in response to endothelium-dependent ( $\mathrm{ACh}$ and insulin) and endothelium-independent (SNP) stimuli (Figure 2). Responses to preconstriction with U-46619 were not significantly different between the cohorts (prior to $\mathrm{ACh}, p=0.48$; prior to insulin, $p=0.23$; prior to SNP, $p=0.68$, data not shown). LM-Ang II mice exhibited impaired vasodilatory responses to ACh compared to the LM-saline cohort, and MR deletion in myeloid cells restored this response (Figure 2A). Similar observations were made in response to insulin; however, these effects did not reach statistical significance (Figure 2B). Ang II also resulted in impaired endothelial-independent vasorelaxation that was not significantly reverted in the MyMRKO-Ang II cohort. Collectively, these findings suggest that myeloid MR deletion improves endothelial function without affecting smooth muscle relaxation capacity in Ang II-treated mice (Figure 2C).

iNOS is a known marker of macrophage activation (Gunnett et al., 2005; Tejero et al., 2019), also known to be expressed in endothelial cells under inflammatory conditions (Gunnett et al., 2005; Lowry et al., 2013). Its activation can lead to endothelial dysfunction by limiting NO production by endothelial NOS (Ichihara et al., 2000; Gunnett et al., 2005; Tian et al., 2010). Herein, we examined iNOS expression in aortic tissue from the different cohorts (Figure 3A). We show that Ang II infusion results in augmented iNOS expression in endothelial and myeloid cells in the LM-Ang II cohort (Figures 3B,C). This increased expression in endothelial cells was ameliorated by myeloid MR deletion (Figures 3B,C), while there was a trend $(p=0.07)$ toward decreased expression in myeloid cells (Figure 3C).

The presence of local RAAS in VAT and in PVAT has been shown to promote oxidative stress and vascular dysfunction (Agabiti-Rosei et al., 2018). Interestingly, the phenotype of PVAT varies according to the different sections of the aorta, with the thoracic aorta region mimicking the morphology of brown adipose tissue, whereas white adipose tissue predominates in the abdominal aorta (Lian and Gollasch, 2016). Therefore, we examined the impact of MR activation in myeloid cells in response to Ang II in tPVAT, aPVAT, and VAT via immunohistochemistry (IHC), RT-PCR, and/or FACS.

As shown in Figure 4, Ang II resulted in increased macrophage infiltration (assessed by Mac-2 staining) compared to control in VAT, and deletion of MR in myeloid cells reversed it. Further, in TPVAT, our PCR studies showed that knockout of $\mathrm{MR}$ in myeloid cells caused significant reductions in markers for total macrophages as well as M1 polarization, including CD68, CD11c, NOX2, and tumor necrosis factor (TNF)- $\alpha$ relative to LM-Ang II, along with a trend for a reduction of interleukin (IL)$6 \beta$ (Figure 5A). Conversely, no significant differences between groups or interventions were found in aPVAT (Figure 5B). In VAT, TNF- $\alpha$ was significantly lower in $\mathrm{KO}$ animals relative to littermates infused with Ang II (Figure 5C).

To precisely assess the impact of myeloid MR knockout in fat inflammation in a separate cohort of mice, we utilized flow cytometry to evaluate macrophage infiltration and polarization phenotype in VAT. Previous investigations have shown that Ang II infusion results in inflammation of both adipose and cardiovascular tissues (Police et al., 2009; Usher et al., 2010; Sakaue et al., 2017). Similarly, in the present investigation, we showed that Ang II infusion resulted in increased macrophage infiltration in adipose tissue when compared to the saline-treated cohort (Figure 4). To further assess the impact of myeloid MR deletion on Ang-II-induced adipose inflammation, we focused our FACS studies on characterizing the specific macrophage polarization status of VAT in mice (LM and MyMRKO) infused with Ang II. As shown in Figure 6, MyMRKO was associated with reduced infiltration/M1 macrophage polarization in response to Ang II infusion.

Collectively, our data in vivo and ex vivo show that MR abrogation in myeloid cells is protective against Ang II-induced aortic endothelial stiffening and dysfunction. These changes occurred in concert with improvements in macrophage infiltration and pro-inflammatory M1 polarization in VAT and tPVAT. 


\section{-o- LM-Saline - LM-Ang II -O- MyMRKO-Ang II}

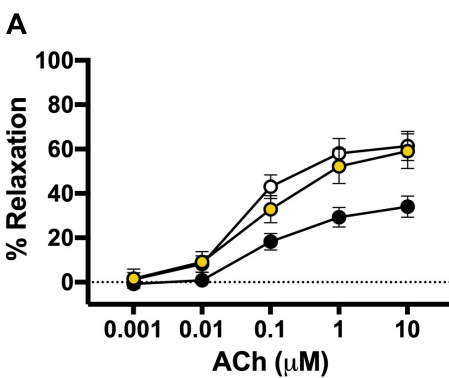

B

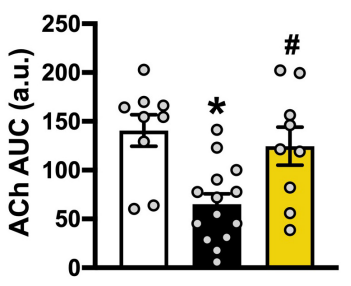

C

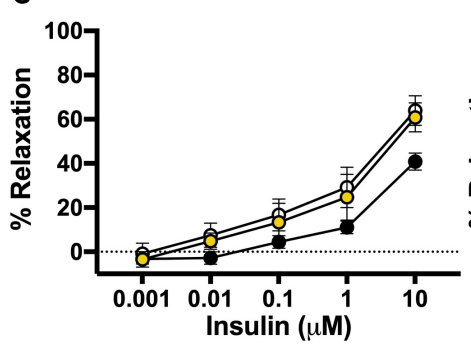

D

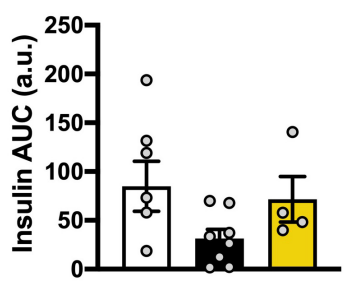

E

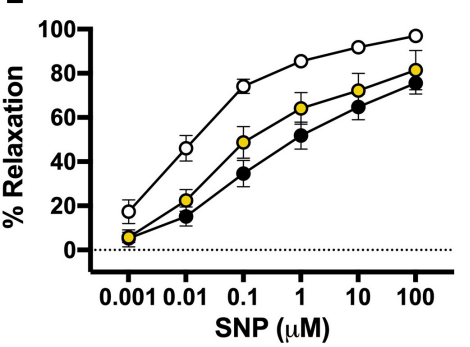

$\mathbf{F}$

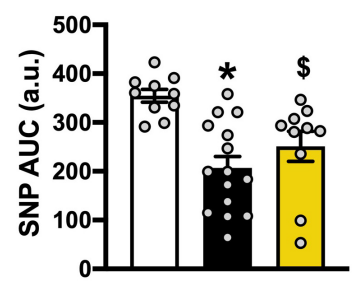

FIGURE 2 | Deletion of myeloid cell MR improves endothelial function in Ang II-infused mice. Aortic vasomotor responses to acetylcholine (ACh) [(A) response curve, (B) area under the curve (AUC)], insulin (C,D), and sodium nitroprusside (SNP) (E,F). ${ }^{*} p \leq 0.05$ LM-Ang II vs. LM-Saline; ${ }^{*} p \leq 0.05$ LM-Ang II vs. MyMRKO-Ang II; ${ }^{\$} p \leq 0.05$ MyMRKO-Ang II vs. LM-Saline. $n=4-15$ for all groups. LM, littermate; Ang II, angiotensin II; MyMRKO, myeloid mineralocorticoid receptor knockout.

\section{DISCUSSION}

In the present study, we demonstrate that abrogation of MR signaling in myeloid cells in female mice protects against the development of aortic stiffening and improves endothelial function, independently of blood pressure changes and vascular smooth muscle relaxation capacity. These effects occurred in the setting of enhanced MR activation induced by Ang II infusion over 4 weeks. Furthermore, we show that vascular protection with MR deletion in myeloid cells is associated with a reduction in markers of macrophage infiltration and pro-inflammatory M1 macrophage polarization in tPVAT and in VAT. Our work expands upon previous knowledge regarding the role of immune cells as critical mediators of vascular stiffening in conditions of enhanced MR activation specifically affecting females.

Previous work has shown that MR abrogation in myeloid cells protects against cardiac and vascular inflammation, hypertrophy, and fibrosis induced by RAAS activation in male mice (Rocha et al., 2000; Rickard et al., 2009; Usher et al., 2010). Herein, we demonstrate that MyMRKO in female mice protects against aortic stiffening and improves endothelial function and in Ang II-infused mice. These changes were associated with decreased iNOS expression in the vascular wall, possibly reflecting lessened inflammation and increased NO bioavailability (Gunnett et al., 2005). However, future additional studies aimed at isolating specific cell types (e.g., myeloid cells and endothelial cells) are required to dissect the effects of MyMRKO on the recruitment of inflammatory cells and subsequent iNOS activation.

Since it has been previously demonstrated that AChinduced aortic vasodilator responses are highly NO dependent
(Chataigneau et al., 1999; Balarini et al., 2013; Crissey et al., 2015), it is reasonable to suggest that the impaired ACh and SNP vasorelaxation responses observed in our Ang II infusion model are secondary to decreased NO bioavailability and smooth muscle stiffening, as reported by others (Imanishi et al., 2006; Hong et al., 2015). Indeed, lessened NO bioavailability and Ang II exposure are known to result in aortic and vascular smooth muscle stiffening, respectively (Fitch et al., 2001). Given the extensive evidence linking adipose tissue inflammation and oxidative stress with decreased vascular NO bioavailability (Akoumianakis and Antoniades, 2017; Oikonomou and Antoniades, 2019), it is conceivable that in this model of myeloid MR deletion, decreased adipose tissue inflammation is linked to improved vascular function. It should be noted that myeloid MR deletion did not restore endothelium-independent vasodilatory responses to SNP. This suggests that the improved relaxation responses to $\mathrm{ACh}$ in the MyMRKO-Ang II cohort were the result of increased NO bioavailability rather than the improved capacity of smooth muscle to respond to a given concentration of NO.

In our investigation, myeloid MR deletion did not impact blood pressure elevation induced by Ang II infusion. This is similar to previous experiments in MyMRKO male mice treated with L-NAME/Ang II in which blood pressure responses were independent of other cardiovascular outcomes (Usher et al., 2010; Frieler et al., 2011; Li et al., 2014). Nevertheless, we demonstrate that myeloid MR deletion abrogates arterial stiffening induced by Ang II. This is clinically relevant given that aortic stiffening has been extensively associated with cardiovascular mortality and morbidity independently of changes in blood pressure in large cohorts (Mitchell et al., 2010; Aroor et al., 2013). Our 
A
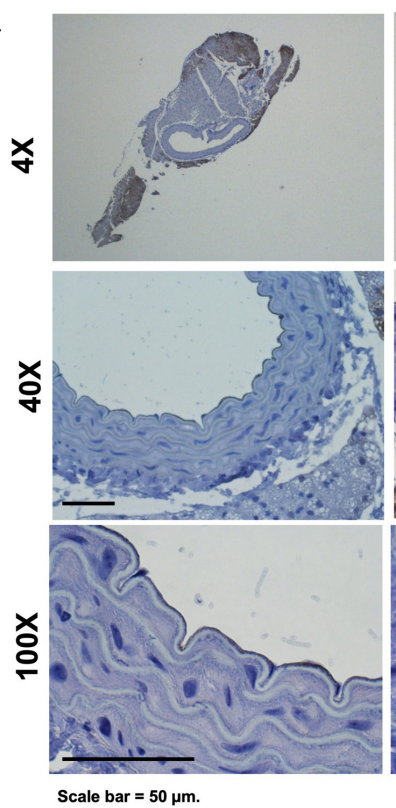

B

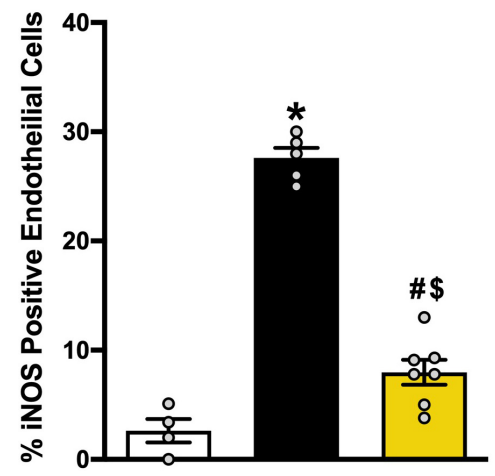

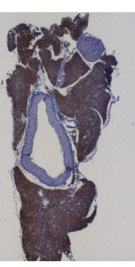
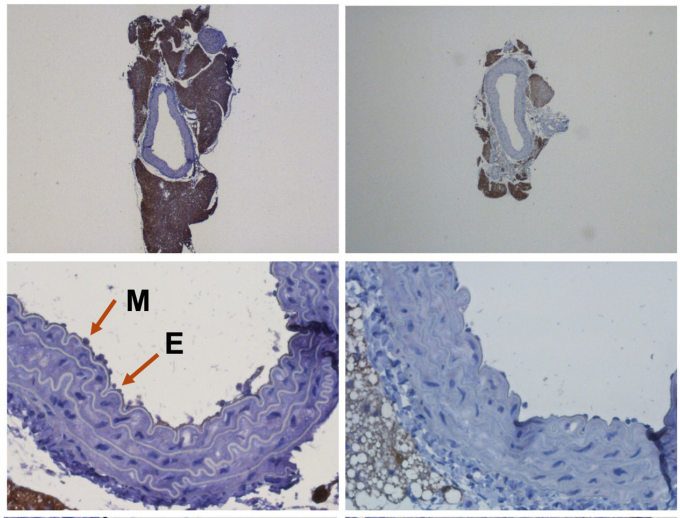

E

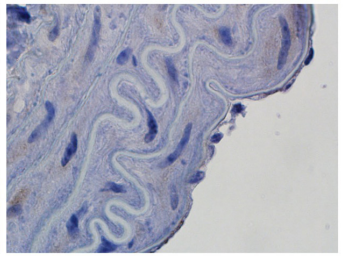

C

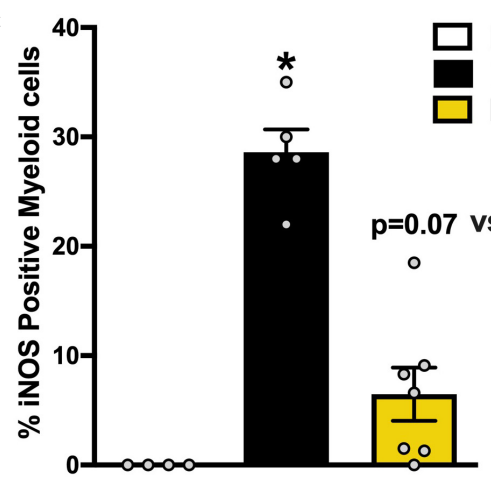

FIGURE 3 | Deletion of myeloid cell MR decreases Ang II-induced iNOS expression in myeloid and endothelial cells. (A) Representative images of iNOS staining in myeloid and endothelial cells at 4x,40x, and 100xof the different cohorts. (B) iNOS-positive endothelial cells and (C) iNOS-positive myeloid cells. Results are expressed as percent positive cells. ${ }^{*} p \leq 0.05$ LM-Ang II vs. LM-Saline; ${ }^{\$} p \leq 0.05$ MyMRKO-Ang II vs. LM-Saline; ${ }^{*} p \leq 0.05$ LM-Ang $\|$ vs. MyMRKO-Ang II. $n=4-7$ for all groups. iNOS, inducible nitric oxide synthase; LM, littermate; Ang II, angiotensin II; MyMRKO, myeloid mineralocorticoid receptor knockout.

study further extends our knowledge on the role of myeloid MR activation in mediating vascular stiffening in female mice, which have been shown to be more vulnerable to vascular dysfunction in the setting of elevated aldosterone levels when compared with males (Manrique et al., 2016; Davel et al., 2018). In this study, we did not compare females to males; however, our data support the notion that MR activation contributes to profound vascular dysfunction in females in conditions of enhanced RAAS activity such as obesity and insulin resistance (Mehta et al., 2016; Davel et al., 2018; Nayyar et al., 2018; Shukri et al., 2018).

Current literature supports a critical role for adipose tissue in the pathogenesis of CVD (Oikonomou and Antoniades, 2019) by acting as a source of inflammation that leads to dysfunction of cardiac and vascular tissues. In the present investigation, we observed a reduction in markers of macrophage infiltration and M1 polarization induced by Ang-II in female mice lacking MR in myeloid cells in VAT and tPVAT, thus expanding knowledge about the scope of MR activation on the development of vascular dysfunction in females.

Importantly, although we found improvements of Ang II-induced endothelial stiffness and endothelial function in females lacking myeloid MR along with decreased macrophage infiltration and M1 polarization in tPVAT, our data do not demonstrate a causative link. However, available literature supports a critical role for PVAT in modulating the structure and function of the underlying vasculature (Cheng et al., 2018; Qiu et al., 2018), and our findings in PVAT are in line with this possibility. Similarly, our data in VAT also suggest an impact on vascular function, since MR activation in VAT is known to play a critical role in the development of vascular stiffening and endothelial dysfunction (Nguyen Dinh Cat et al., 2016; Jia et al., 2017; Lefranc et al., 2019). Certainly, additional mechanistic studies are warranted to explore the potential mechanisms that link MR activation in specific adipose 


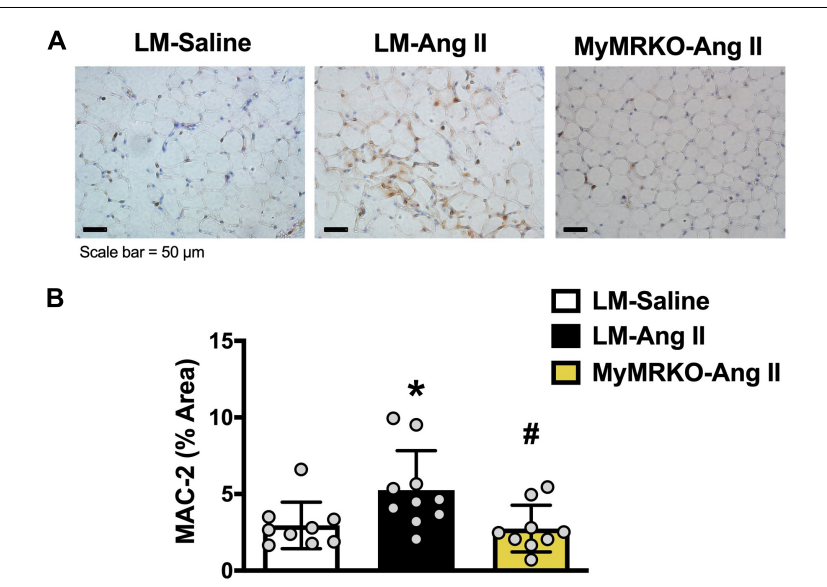

FIGURE 4 | Macrophage infiltration in visceral adipose tissue is decreased in MyMRKO mice. Representative image of Mac-2 staining in visceral adipose tissue (VAT) of the different cohorts (A); Mac-2 staining quantification (B). ${ }^{*} p \leq 0.05$ LM-Ang II vs. LM-Saline; ${ }^{*} p \leq 0.05$ LM-Ang II vs. MyMRKO-Ang II. $n=9-10$ for all groups. LM, littermate; Ang II, angiotensin II; MyMRKO, myeloid mineralocorticoid receptor knockout.

tissue compartments such as PVAT and dysfunction of the underlying vasculature.

In our adipose tissue analysis, we included VAT, tPVAT, and aPVAT. tPVAT is morphologically and functionally different from aPVAT and VAT, as it expresses genes specific to brown adipose tissue that promote thermogenesis, lipid oxidation, and insulin sensitivity (Fitzgibbons et al., 2011). Furthermore, the presence of immune cells, in particular macrophages, is notoriously lower in tPVAT than VAT and aPVAT (Fitzgibbons et al., 2011; Padilla et al., 2013). These features highlight a protective role of tPVAT under physiologic conditions (Nosalski and Guzik, 2017; Horimatsu et al., 2018). Although our study does not focus on detecting "browning" or "whitening" changes on adipose tissue, we speculate that the Ang II impact can be at least partially related to a myeloid MR-driven shift toward a white adipose tissue phenotype. Indeed, "whitening" of adipose tissue has been described in response to different stimuli capable of inducing macrophage infiltration (Kotzbeck et al., 2018), such as Ang II (Kawabe et al., 2019). In line with our findings, other investigators have reported that Ang II infusion in mice also results in stiffening of the abdominal aorta (Tham et al., 2002), which is surrounded by aPVAT. Therefore, it is likely that our findings in the thoracic aorta also occurred in the abdominal aorta. Although our findings using PCR were not statistically significant, we demonstrate a protective effect of $\mathrm{MR} \mathrm{KO}$ in myeloid cells against Ang II-induced macrophage infiltration/M1 polarization in VAT. This apparent disparity can be explained by the use of IHC and flow cytometry, which more specifically targets macrophage markers in VAT, whereas PCR was utilized to analyze whole aPVAT tissue.

A limitation of the MyMRKO model is that the $\mathrm{KO}$ affects the whole myeloid lineage and not only macrophages. Available data in this regard are still sparse; however, the degree of MR abrogation specifically in macrophages appears to be predominant over other types of myeloid cells (Usher et al., 2010) and has been reported to be as high as $80 \%$ in macrophages, whereas it is significantly lower (approximately 50\%) in circulating neutrophils (Huang et al., 2014). Another confounding factor inherent to the MyMRKO model is that MR expression is abrogated in myeloid cells independently of their origin and not exclusively in adipose tissue. Therefore, we cannot exclude an impact of MR abrogation in other tissues on our findings in the vasculature. Also, the impact of MRKO is variable in different cell types. While there is incomplete abrogation in resident peritoneal macrophages $(30-40 \%)$ as well in the brain (Cho et al., 2008), there is near-absolute abolition of MR expression
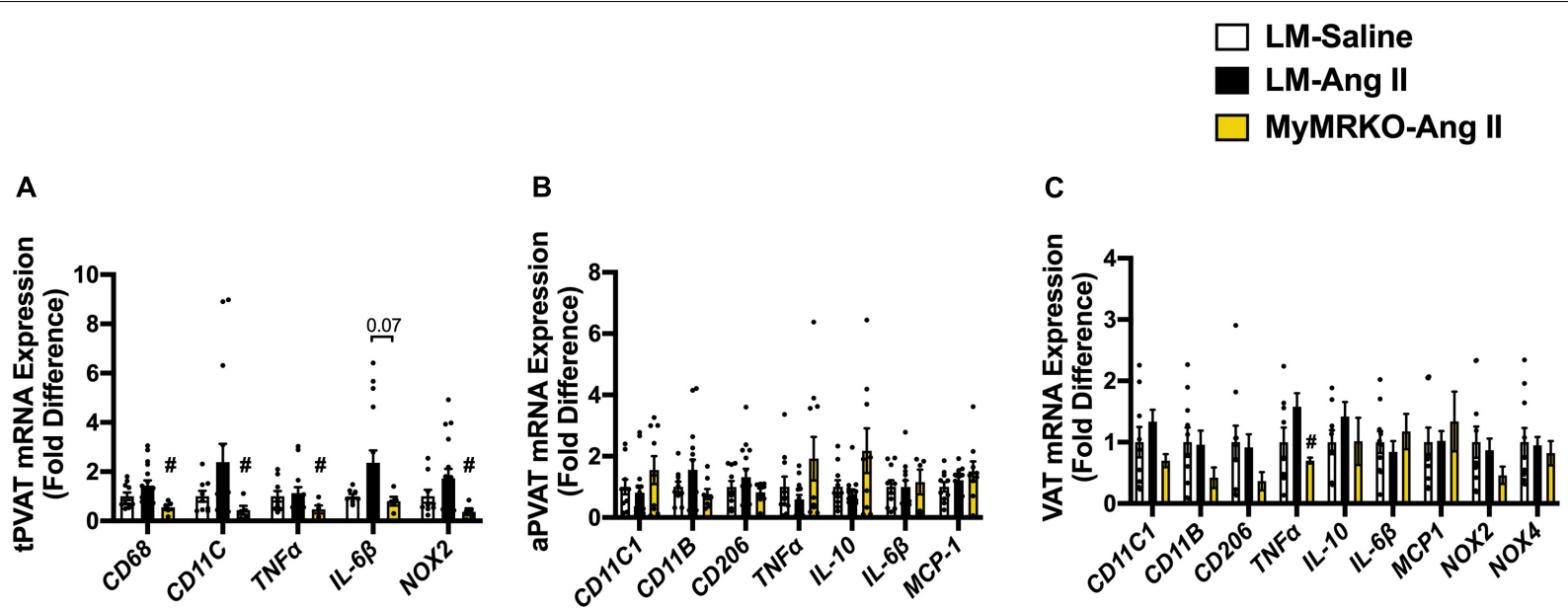

FIGURE 5 | Markers of macrophage infiltration and polarization in different fat depots. (A) Thoracic perivascular adipose tissue (tPVAT), (B) abdominal perivascular adipose tissue (aPVAT), and (C) visceral adipose tissue (VAT). Total macrophage expression (CD11b), M1 macrophage expression (MCP-1), and M2 macrophage polarization (IL-10). ${ }^{*} p \leq 0.05$, LM-Ang II vs. MyMRKO-Ang II. $n=9$-10 for all groups. LM, littermate; Ang II, angiotensin II; MyMRKO, myeloid mineralocorticoid receptor knockout. 


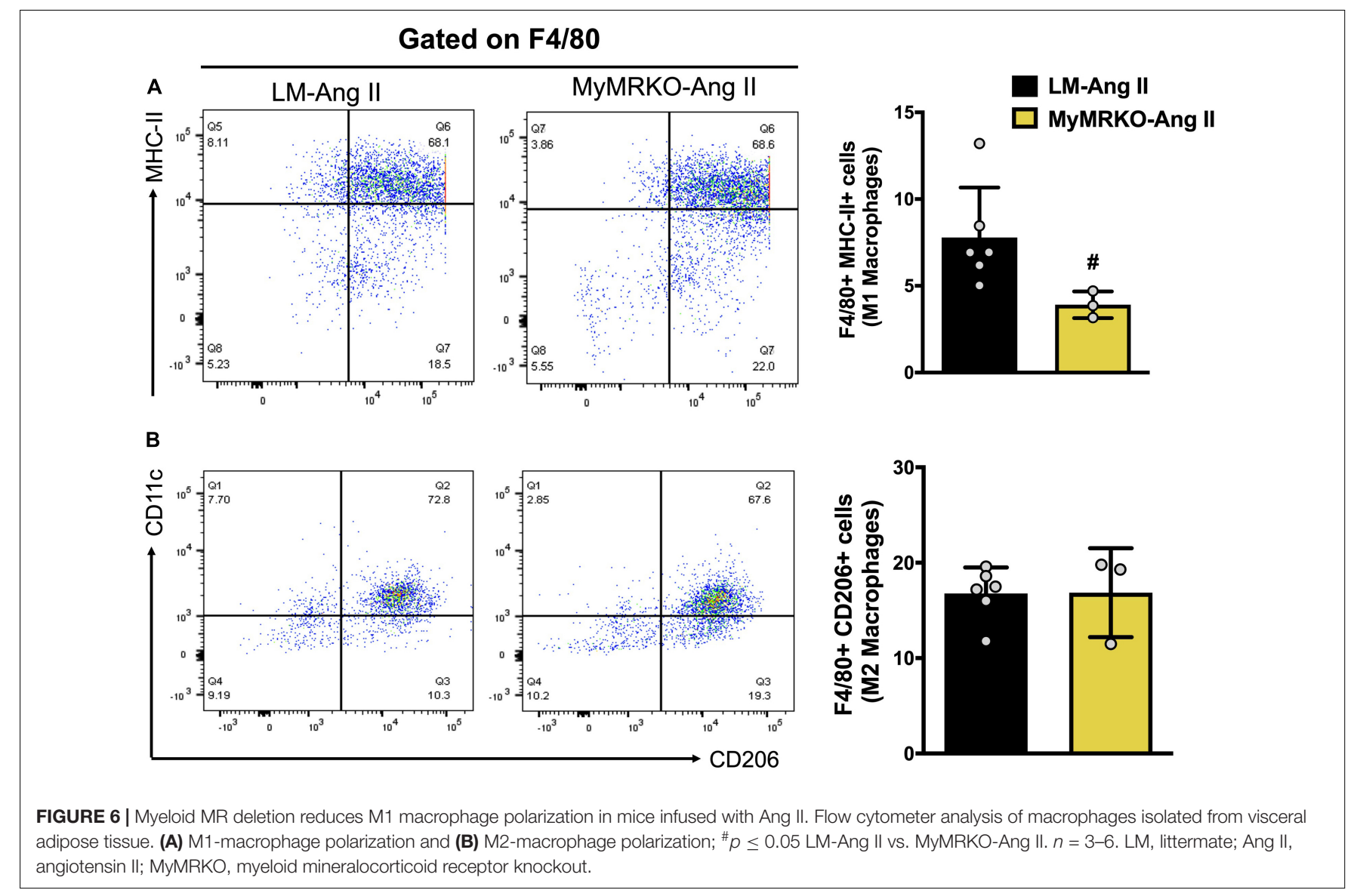

in heart tissue (Usher et al., 2010). In addition, it is also important to highlight that macrophages do not express $11 \beta$-hydroxysteroid dehydrogenase type 2 , the enzyme that inactivates glucocorticoids and provides specificity to mineralocorticoid actions. Therefore, MR activation in macrophages is likely to be mediated instead by glucocorticoids (Rickard et al., 2009; Usher et al., 2010), although direct MR activation by Ang II has been described (Lu et al., 2019). Despite these limitations of the MyMRKO model, our findings support a critical role for myeloid cells, in particular macrophages, as potential mediators of vascular injury resulting from inappropriate MR activation.

Collectively, our study adds to mounting evidence in both preclinical models and clinical studies demonstrating a critical role of inappropriate MR activation and enhanced mineralocorticoid activity that profoundly affects vascular function in females and potentially contributes to more severe CVD relative to males (Manrique et al., 2016; Mehta et al., 2016; Lastra et al., 2017). In the present study, we demonstrate that MR activation in myeloid cells is critical to the development of vascular stiffness and abnormal vasomotor responses in a female mouse model of MR activation. Further, our data suggest that enhanced MR signaling predominantly in macrophages promotes vascular stiffness and endothelial dysfunction in concert with enhanced M1 macrophage polarization and inflammation in VAT as well as PVAT. These novel data add to current knowledge about the role played by MR activation in myeloid cells in the pathogenesis of vascular dysfunction and contribute to a better understanding of the pathophysiology of CVD in females, who are disproportionately more affected in conditions of RAAS activation relative to men.

\section{DATA AVAILABILITY STATEMENT}

The raw data supporting the conclusions of this article will be made available by the authors, without undue reservation.

\section{ETHICS STATEMENT}

The animal study was reviewed and approved by Institutional Animal Use and Care Committee (IACUC) at the University of Missouri-Columbia.

\section{AUTHOR CONTRIBUTIONS}

All authors listed have made a substantial, direct and intellectual contribution to the work, and approved it for publication. 


\section{FUNDING}

This work was supported by the Veterans Administration (VA) Merit grant 5I01BX001981 to GL and by the National Institutes of Health (R01 HL088105 to LM-L, R01HL142770 to CM-A, K08HL132012 to GL, R01HL124155 to $\mathrm{CH})$.

\section{REFERENCES}

Agabiti-Rosei, C., Paini, A., De Ciuceis, C., Withers, S., Greenstein, A., Heagerty, A. M., et al. (2018). Modulation of vascular reactivity by perivascular adipose tissue (PVAT). Curr. Hypertens. Rep. 20:44. doi: 10.1007/s11906-018-0835-5

Akoumianakis, I., and Antoniades, C. (2017). The interplay between adipose tissue and the cardiovascular system: Is fat always bad? Cardiovasc. Res. 113, 999-1008. doi: 10.1093/cvr/cvx111

Aroor, A. R., Demarco, V. G., Jia, G., Sun, Z., Nistala, R., Meininger, G. A., et al. (2013). The role of tissue Renin-Angiotensin-aldosterone system in the development of endothelial dysfunction and arterial stiffness. Front. Endocrinol. 4:161. doi: 10.3389/fendo.2013.00161

Balarini, C. M., Leal, M. A., Gomes, I. B., Pereira, T. M., Gava, A. L., Meyrelles, S. S., et al. (2013). Sildenafil restores endothelial function in the apolipoprotein E knockout mouse. J. Transl. Med. 11:3. doi: 10.1186/1479-5876-11-3

Berger, S., Wolfer, D. P., Selbach, O., Alter, H., Erdmann, G., Reichardt, H. M., et al. (2006). Loss of the limbic mineralocorticoid receptor impairs behavioral plasticity. Proc. Natl. Acad. Sci. U.S.A. 103, 195-200. doi: 10.1073/pnas. 0503878102

Bjørndal, B., Burri, L., Staalesen, V., Skorve, J., and Berge, R. K. (2011). Different adipose depots: their role in the development of metabolic syndrome and mitochondrial response to hypolipidemic agents. J. Obes. 2011:490650. doi: 10.1155/2011/490650

Brown, N. K., Zhou, Z., Zhang, J., Zeng, R., Wu, J., Eitzman, D. T., et al. (2014). Perivascular adipose tissue in vascular function and disease: a review of current research and animal models. Arterioscler. Thromb. Vasc. Biol. 34, 1621-1630. doi: 10.1161/atvbaha.114.303029

Brown, S. M., Smith, C. E., Meuth, A. I., Khan, M., Aroor, A. R., Cleeton, H. M., et al. (2017). Dipeptidyl peptidase-4 inhibition with saxagliptin ameliorates angiotensin II-induced cardiac diastolic dysfunction in male mice. Endocrinology 158, 3592-3604. doi: 10.1210/en.2017-00416

Bustin, S. A., Benes, V., Garson, J. A., Hellemans, J., Huggett, J., Kubista, M., et al. (2009). The MIQE guidelines: minimum information for publication of quantitative real-time PCR experiments. Clin. Chem. 55, 611-622. doi: 10.1373/ clinchem.2008.112797

Chataigneau, T., Félétou, M., Huang, P. L., Fishman, M. C., Duhault, J., and Vanhoutte, P. M. (1999). Acetylcholine-induced relaxation in blood vessels from endothelial nitric oxide synthase knockout mice. Br. J. Pharmacol. 126, 219-226. doi: 10.1038/sj.bjp.0702300

Cheng, C. K., Bakar, H. A., Gollasch, M., and Huang, Y. (2018). Perivascular adipose tissue: the sixth man of the cardiovascular system. Cardiovasc. Drugs Ther. 32, 481-502. doi: 10.1007/s10557-018-6820-z

Cho, I.-H., Hong, J., Suh, E. C., Kim, J. H., Lee, H., Lee, J. E., et al. (2008). Role of microglial IKKbeta in kainic acid-induced hippocampal neuronal cell death. Brain 131(Pt 11), 3019-3033. doi: 10.1093/brain/awn230

Chusyd, D. E., Wang, D., Huffman, D. M., and Nagy, T. R. (2016). Relationships between rodent white adipose fat pads and human white adipose fat depots. Front. Nutr. 3:10. doi: 10.3389/fnut.2016.00010

Crissey, J. M., Padilla, J., Vieira-Potter, V. J., Thorne, P. K., Koch, L. G., Britton, S. L., et al. (2015). Divergent role of nitric oxide in insulin-stimulated aortic vasorelaxation between low- and high-intrinsic aerobic capacity rats. Physiol. Rep. 3:e12459. doi: 10.14814/phy2.12459

Davel, A. P., Lu, Q., Moss, M. E., Rao, S., Anwar, I. J., DuPont, J. J., et al. (2018). Sex-specific mechanisms of resistance vessel endothelial dysfunction induced by cardiometabolic risk factors. J. Am. Heart Assoc. 7:e007675. doi: 10.1161/ jaha.117.007675

Dos Reis Costa, D. E. F., Silveira, A. L. M., Campos, G. P., Nóbrega, N. R. C., de Araújo, N. F., de Figueiredo Borges, L., et al. (2020). High-carbohydrate

\section{ACKNOWLEDGMENTS}

We acknowledge Dr. Richard M. Mortensen, MD, Ph.D., Professor at the Department of Pharmacology at the University of Michigan School of Medicine for his help in originally providing the MyMRKO mouse model. We also thank Dongqing Chen and Matthew B. Martin for excellent technical assistance.

diet enhanced the anticontractile effect of perivascular adipose tissue through activation of renin-angiotensin system. Front. Physiol. 11:628101. doi: 10.3389/ fphys.2020.628101

Fitch, R. M., Vergona, R., Sullivan, M. E., and Wang, Y. X. (2001). Nitric oxide synthase inhibition increases aortic stiffness measured by pulse wave velocity in rats. Cardiovasc. Res. 51, 351-358. doi: 10.1016/s0008-6363(01)00299-1

Fitzgibbons, T. P., Kogan, S., Aouadi, M., Hendricks, G. M., Straubhaar, J., and Czech, M. P. (2011). Similarity of mouse perivascular and brown adipose tissues and their resistance to diet-induced inflammation. Am. J. Physiol. Heart Circ. Physiol. 301, H1425-H1437. doi: 10.1152/ajpheart.00376.2011

Fox, C. S., Massaro, J. M., Hoffmann, U., Pou, K. M., Maurovich-Horvat, P. Liu, C. Y., et al. (2007). Abdominal visceral and subcutaneous adipose tissue compartments: association with metabolic risk factors in the Framingham Heart Study. Circulation 116, 39-48. doi: 10.1161/circulationaha.106.67 5355

Frieler, R. A., Meng, H., Duan, S. Z., Berger, S., Schutz, G., He, Y., et al. (2011). Myeloid-specific deletion of the mineralocorticoid receptor reduces infarct volume and alters inflammation during cerebral ischemia. Stroke 42, 179-185. doi: 10.1161/strokeaha.110.598441

Goodpaster, B. H., Krishnaswami, S., Resnick, H., Kelley, D. E., Haggerty, C., Harris, T. B., et al. (2003). Association between regional adipose tissue distribution and both type 2 diabetes and impaired glucose tolerance in elderly men and women. Diabetes Care 26, 372-379. doi: 10.2337/diacare.26.2.372

Grunewald, Z. I., Jurrissen, T. J., Woodford, M. L., Ramirez-Perez, F. I., Park, L. K., Pettit-Mee, R., et al. (2019). Chronic elevation of endothelin-1 alone may not be sufficient to impair endothelium-dependent relaxation. Hypertension 74, 1409-1419. doi: 10.1161/hypertensionaha.119.13676

Gunnett, C. A., Lund, D. D., McDowell, A. K., Faraci, F. M., and Heistad, D. D. (2005). Mechanisms of inducible nitric oxide synthase-mediated vascular dysfunction. Arterioscler. Thromb. Vasc. Biol. 25, 1617-1622. doi: 10.1161/01. ATV.0000172626.00296.ba

Hans, C. P., Koenig, S. N., Huang, N., Cheng, J., Beceiro, S., Guggilam, A., et al. (2012). Inhibition of Notch1 signaling reduces abdominal aortic aneurysm in mice by attenuating macrophage-mediated inflammation. Arterioscler. Thromb. Vasc. Biol. 32, 3012-3023. doi: 10.1161/atvbaha.112.254219

Hong, Z., Reeves, K. J., Sun, Z., Li, Z., Brown, N. J., and Meininger, G. A. (2015). Vascular smooth muscle cell stiffness and adhesion to collagen I modified by vasoactive agonists. PLoS One 10:e0119533. doi: 10.1371/journal.pone.0119533

Horimatsu, T., Patel, A. S., Prasad, R., Reid, L. E., Benson, T. W., Zarzour, A., et al. (2018). Remote effects of transplanted perivascular adipose tissue on endothelial function and atherosclerosis. Cardiovasc. Drugs Ther. 32, 503-510. doi: 10.1007/s10557-018-6821-y

Huang, L. L., Nikolic-Paterson, D. J., Han, Y., Ozols, E., Ma, F. Y., Young, M. J., et al. (2014). Myeloid mineralocorticoid receptor activation contributes to progressive kidney disease. J. Am. Soc. Nephrol. 25, 2231-2240. doi: 10.1681/ asn.2012111094

Huang, Z. H., Manickam, B., Ryvkin, V., Zhou, X. J., Fantuzzi, G., Mazzone, T., et al. (2013). PCOS is associated with increased CD11c expression and crownlike structures in adipose tissue and increased central abdominal fat depots independent of obesity. J. Clin. Endocrinol. Metab. 98, E17-E24. doi: 10.1210/ jc. $2012-2697$

Hussain, T., Hong, M., Osmond, P. J., and Izzo, J. L. (2014). Protective effects of amiloride monotherapy on blood pressure, hemodynamics, and arterial stiffness in glucocorticoid-remediable aldosteronism (GRA). J. Am. Soc. Hypertens. 8, e137-e138. doi: 10.1016/j.jash.2014.03.312

Ichihara, A., Hayashi, M., Navar, L. G., and Saruta, T. (2000). Inducible nitric oxide synthase attenuates endothelium-dependent renal microvascular vasodilation. J. Am. Soc. Nephrol. 11, 1807-1812. 
Imanishi, T., Kobayashi, K., Kuroi, A., Mochizuki, S., Goto, M., Yoshida, K., et al. (2006). Effects of angiotensin II on NO bioavailability evaluated using a catheter-type NO sensor. Hypertension 48, 1058-1065. doi: 10.1161/01.HYP. 0000248920.16956.d8

Jain, S., Khera, R., Corrales-Medina, V. F., Townsend, R. R., and Chirinos, J. A. (2014). Inflammation and arterial stiffness in humans. Atherosclerosis 237, 381-390. doi: 10.1016/j.atherosclerosis.2014.09.011

Jaisser, F., and Farman, N. (2016). Emerging roles of the mineralocorticoid receptor in pathology: toward new paradigms in clinical pharmacology. Pharmacol. Rev. 68, 49-75. doi: 10.1124/pr.115.011106

Jia, G., Aroor, A. R., and Sowers, J. R. (2017). The role of mineralocorticoid receptor signaling in the cross-talk between adipose tissue and the vascular wall. Cardiovasc. Res. 113, 1055-1063. doi: 10.1093/cvr/cvx097

Kaess, B. M., Rong, J., Larson, M. G., Hamburg, N. M., Vita, J. A., Levy, D., et al. (2012). Aortic stiffness, blood pressure progression, and incident hypertension. JAMA 308, 875-881. doi: 10.1001/2012.jama.10503

Kawabe, Y., Mori, J., Morimoto, H., Yamaguchi, M., Miyagaki, S., Ota, T., et al. (2019). ACE2 exerts anti-obesity effect via stimulating brown adipose tissue and induction of browning in white adipose tissue. Am. J. Physiol. Endocrinol. Metab. 317, E1140-E1149. doi: 10.1152/ajpendo.00311.2019

Klein, S. (2004). The case of visceral fat: argument for the defense. J. Clin. Invest. 113, 1530-1532. doi: 10.1172/jci22028

Kotzbeck, P., Giordano, A., Mondini, E., Murano, I., Severi, I., Venema, W., et al. (2018). Brown adipose tissue whitening leads to brown adipocyte death and adipose tissue inflammation. J. Lipid Res. 59, 784-794. doi: 10.1194/jlr.M079665

Kraakman, M. J., Murphy, A. J., Jandeleit-Dahm, K., and Kammoun, H. L. (2014). Macrophage polarization in obesity and type 2 diabetes: Weighing down our understanding of macrophage function? Front. Immunol. 5:470. doi: 10.3389/ fimmu.2014.00470

Lastra, G., and Manrique, C. (2015). Perivascular adipose tissue, inflammation and insulin resistance: link to vascular dysfunction and cardiovascular disease. Horm. Mol. Biol. Clin. Invest. 22, 19-26. doi: 10.1515/hmbci-2015-0010

Lastra, G., Manrique, C., Jia, G., Aroor, A. R., Hayden, M. R., Barron, B. J., et al. (2017). Xanthine oxidase inhibition protects against Western diet-induced aortic stiffness and impaired vasorelaxation in female mice. Am. J. Physiol. Regul. Integr. Comp. Physiol. 313, R67-R77. doi: 10.1152/ajpregu.00483.2016

Lastra, G., Manrique, C., and Sowers, J. R. (2008). "Renin-angiotensin system proteases and the cardiometabolic syndrome: pathophysiological, clinical and therapeutic implications," in Frontiers in Research of the Renin-Angiotensin System on Human Disease, ed. P. S. Leung (Dordrecht: Springer), 87-111.

Lee, W. J., Tateya, S., Cheng, A. M., Rizzo-DeLeon, N., Wang, N. F., Handa, P., et al. (2015). M2 macrophage polarization mediates anti-inflammatory effects of endothelial nitric oxide signaling. Diabetes 64, 2836-2846. doi: 10.2337/db141668

Lefranc, C., Friederich-Persson, M., Braud, L., Palacios-Ramirez, R., Karlsson, S., Boujardine, N., et al. (2019). (Mineralocorticoid Receptor) induces adipose tissue senescence and mitochondrial dysfunction leading to vascular dysfunction in obesity. Hypertension 73, 458-468. doi: 10.1161/HYPERTENSIONAHA.118.11873

Li, C., Zhang, Y. Y., Frieler, R. A., Zheng, X. J., Zhang, W. C., Sun, X. N., et al. (2014). Myeloid mineralocorticoid receptor deficiency inhibits aortic constriction-induced cardiac hypertrophy in mice. PLoS One 9:e110950. doi: 10.1371/journal.pone.0110950

Lian, X., and Gollasch, M. A. (2016). Clinical perspective: contribution of dysfunctional perivascular adipose tissue (PVAT) to cardiovascular risk. Curr. Hypertens. Rep. 18:82. doi: 10.1007/s11906-016-0692-z

Lowry, J. L., Brovkovych, V., Zhang, Y., and Skidgel, R. A. (2013). Endothelial nitric-oxide synthase activation generates an inducible nitric-oxide synthaselike output of nitric oxide in inflamed endothelium. J. Biol. Chem. 288, 4174-4193. doi: 10.1074/jbc.M112.436022

Lu, Q., Davel, A. P., McGraw, A. P., Rao, S. P., Newfell, B. G., and Jaffe, I. Z. (2019). PKC $\delta$ mediates mineralocorticoid receptor activation by angiotensin II to modulate smooth muscle cell function. Endocrinology 160, 2101-2114. doi: 10.1210/en.2019-00258

Manrique, C., Lastra, G., Ramirez-Perez, F. I., Haertling, D., DeMarco, V. G., Aroor, A. R., et al. (2016). Endothelial estrogen receptor-alpha does not protect against vascular stiffness induced by western diet in female mice. Endocrinology 157, 1590-1600. doi: 10.1210/en.2015-1681
Mehta, L. S., Beckie, T. M., DeVon, H. A., Grines, C. L., Krumholz, H. M., Johnson, M. N., et al. (2016). Acute myocardial infarction in women. Circulation 133, 916-947. doi: 10.1161/CIR.0000000000000351

Mitchell, G. F., Hwang, S. J., Vasan, R. S., Larson, M. G., Pencina, M. J., Hamburg, N. M., et al. (2010). Arterial stiffness and cardiovascular events: the Framingham Heart Study. Circulation 121, 505-511. doi: 10.1161/ circulationaha.109.886655

Muñoz-Durango, N., Vecchiola, A., Gonzalez-Gomez, L. M., Simon, F., Riedel, C. A., Fardella, C. E., et al. (2015). Modulation of immunity and inflammation by the mineralocorticoid receptor and aldosterone. Biomed Res. Int. 2015:652738. doi: 10.1155/2015/652738

Nayyar, M., Lastra, G., and Acevedo, C. M. (2018). Mineralocorticoids and cardiovascular disease in females with insulin resistance and obesity. Curr. Hypertens. Rep. 20:88. doi: 10.1007/s11906-018-0887-6

Nguyen Dinh Cat, A., Antunes, T. T., Callera, G. E., Sanchez, A., Tsiropoulou, S., Dulak-Lis, M. G., et al. (2016). Adipocyte-specific mineralocorticoid receptor overexpression in mice is associated with metabolic syndrome and vascular dysfunction: role of redox-sensitive PKG-1 and Rho Kinase. Diabetes 65, 2392-2403. doi: 10.2337/db15-1627

Nosalski, R., and Guzik, T. J. (2017). Perivascular adipose tissue inflammation in vascular disease. Br. J. Pharmacol. 174, 3496-3513. doi: 10.1111/bph.13705

Oikonomou, E. K., and Antoniades, C. (2019). The role of adipose tissue in cardiovascular health and disease. Nat. Rev. Cardiol. 16, 83-99. doi: 10.1038/ s41569-018-0097-6

Padilla, J., Jenkins, N. T., Vieira-Potter, V. J., and Laughlin, M. H. (2013). Divergent phenotype of rat thoracic and abdominal perivascular adipose tissues. Am. J. Physiol. Regul. Integr. Comp. Physiol. 304, R543-R552. doi: 10.1152/ajpregu. 00567.2012

Padilla, J., Woodford, M. L., Lastra-Gonzalez, G., Martinez-Diaz, V., Fujie, S., Yang, Y., et al. (2019). Sexual dimorphism in obesity-associated endothelial ENaC activity and stiffening in mice. Endocrinology 160, 2918-2928. doi: 10.1210/en. 2019-00483

Police, S. B., Thatcher, S. E., Charnigo, R., Daugherty, A., and Cassis, L. A. (2009). Obesity promotes inflammation in periaortic adipose tissue and angiotensin II-induced abdominal aortic aneurysm formation. Arterioscler. Thromb. Vasc. Biol. 29, 1458-1464. doi: 10.1161/atvbaha.109.192658

Qiu, T., Li, M., Tanner, M. A., Yang, Y., Sowers, J. R., Korthuis, R. J., et al. (2018). Depletion of dendritic cells in perivascular adipose tissue improves arterial relaxation responses in type 2 diabetic mice. Metabolism 85, 76-89.

Rickard, A. J., Morgan, J., Tesch, G., Funder, J. W., Fuller, P. J., and Young, M. J. (2009). Deletion of mineralocorticoid receptors from macrophages protects against deoxycorticosterone/salt-induced cardiac fibrosis and increased blood pressure. Hypertension 54, 537-543. doi: 10.1161/hypertensionaha.109.13 1110

Rocha, R., Stier, C. T. Jr., Kifor, I., Ochoa-Maya, M. R., Rennke, H. G., Williams, G. H., et al. (2000). Aldosterone: a mediator of myocardial necrosis and renal arteriopathy. Endocrinology 141, 3871-3878. doi: 10.1210/endo.141.10.7711

Sakaue, T., Suzuki, J., Hamaguchi, M., Suehiro, C., Tanino, A., Nagao, T., et al. (2017). Perivascular adipose tissue angiotensin II type 1 receptor promotes vascular inflammation and aneurysm formation. Hypertension 70, 780-789. doi: 10.1161/hypertensionaha.117.09512

Saltiel, A. R., and Olefsky, J. M. (2017). Inflammatory mechanisms linking obesity and metabolic disease. J. Clin. Invest. 127, 1-4. doi: 10.1172/jci92035

Sharma, N., Dev, R., Belenchia, A. M., Aroor, A. R., Whaley-Connell, A., Pulakat, L., et al. (2019). Deficiency of IL12p40 (Interleukin 12 p40) Promotes Ang II (Angiotensin II)-induced abdominal aortic aneurysm. Arterioscler. Thromb. Vasc. Biol. 39, 212-223. doi: 10.1161/atvbaha.118.311969

Shukri, M. Z., Tan, J. W., Manosroi, W., Pojoga, L. H., Rivera, A., Williams, J. S., et al. (2018). Biological sex modulates the adrenal and blood pressure responses to angiotensin II. Hypertension 71, 1083-1090. doi: 10.1161/hypertensionaha. 117.11087

Tarique, M., Naz, H., Saini, C., Suhail, M., Shankar, H., Khanna, N., et al. (2020). Association of IL-10 gene polymorphism with IL-10 secretion by CD4 and $\mathrm{T}$ regulatory cells in human leprosy. Front. Immunol. 11:1974. doi: 10.3389/ fimmu.2020.01974

Tejero, J., Shiva, S., and Gladwin, M. T. (2019). Sources of vascular nitric oxide and reactive oxygen species and their regulation. Physiol. Rev. 99, 311-379. doi: $10.1152 /$ physrev.00036.2017 
Tesch, G. H., and Young, M. J. (2017). Mineralocorticoid receptor signaling as a therapeutic target for renal and cardiac fibrosis. Front. Pharmacol. 8:313. doi: 10.3389/fphar.2017.00313

Tham, D. M., Martin-McNulty, B., Wang, Y. X., Da Cunha, V., Wilson, D. W., Athanassious, C. N., et al. (2002). Angiotensin II injures the arterial wall causing increased aortic stiffening in apolipoprotein E-deficient mice. Am. J. Physiol. Regul. Integr. Comp. Physiol. 283, R1442-R1449. doi: 10.1152/ajpregu.00295. 2002

Tian, J., Yan, Z., Wu, Y., Zhang, S. L., Wang, K., Ma, X. R., et al. (2010). Inhibition of iNOS protects endothelial-dependent vasodilation in aged rats. Acta Pharmacol. Sin. 31, 1324-1328. doi: 10.1038/aps.2010.111

Usher, M. G., Duan, S. Z., Ivaschenko, C. Y., Frieler, R. A., Berger, S., Schütz, G., et al. (2010). Myeloid mineralocorticoid receptor controls macrophage polarization and cardiovascular hypertrophy and remodeling in mice. J. Clin. Invest. 120, 3350-3364. doi: 10.1172/JCI41080

van Bussel, B. C., Schouten, F., Henry, R. M., Schalkwijk, C. G., de Boer, M. R., Ferreira, I., et al. (2011). Endothelial dysfunction and lowgrade inflammation are associated with greater arterial stiffness over a 6year period. Hypertension 58, 588-595. doi: 10.1161/hypertensionaha.111.17 4557

Walker, A. E., Henson, G. D., Reihl, K. D., Morgan, R. G., Dobson, P. S., Nielson, E. I., et al. (2015). Greater impairments in cerebral artery compared with skeletal muscle feed artery endothelial function in a mouse model of increased large artery stiffness. J. Physiol. 593, 1931-1943. doi: 10.1113/jphysiol.2014.28 5338

Weisbrod, R. M., Shiang, T., Al Sayah, L., Fry, J. L., Bajpai, S., Reinhart-King, C. A., et al. (2013). Arterial stiffening precedes systolic hypertension in diet-induced obesity. Hypertension 62, 1105-1110. doi: 10.1161/hypertensionaha.113.01744

Winn, N. C., Jurrissen, T. J., Grunewald, Z. I., Cunningham, R. P., Woodford, M. L., Kanaley, J. A., et al. (2019). Estrogen receptor- $\alpha$ signaling maintains immunometabolic function in males and is obligatory for exercise-induced amelioration of nonalcoholic fatty liver. Am. J. Physiol. Endocrinol. Metab. 316, E156-E167. doi: 10.1152/ajpendo.00259.2018

Conflict of Interest: The authors declare that the research was conducted in the absence of any commercial or financial relationships that could be construed as a potential conflict of interest.

Copyright (c) 2021 Manrique-Acevedo, Padilla, Naz, Woodford, Ghiarone, Aroor, Hulse, Cabral-Amador, Martinez-Diaz, Hans, Whaley-Connell, Martinez-Lemus and Lastra. This is an open-access article distributed under the terms of the Creative Commons Attribution License (CC BY). The use, distribution or reproduction in other forums is permitted, provided the original author(s) and the copyright owner(s) are credited and that the original publication in this journal is cited, in accordance with accepted academic practice. No use, distribution or reproduction is permitted which does not comply with these terms. 